\title{
USING THE OCCUPATIONAL PERSONALITY QUESTIONNAIRE (OPQ) FOR MEASURING BROAD TRAITS
}

\author{
DELÉNE VISSER \\ J. M. DU TOIT \\ Programme in Industrial Psychology \\ Department of Human Resource Management \\ Rand Afrikaans University
}

\begin{abstract}
The widespread acceptance of the Big Five model implies that personality consists of relatively independent dimensions that form a taxonomy whereby individual differences may be explained. The purpose of this study was to investigate whether the subscales of an established personality inventory that measures narrow traits of personality, the Occupational Personality Questionnaire (OPQ), could be reduced meaningfully to fit a broad factor model within a South African context. The OPQ 5.2 concept model was administered to 453 job applicants in the telecommunications sector. An exploratory factor analysis yielded a six-factor structure that included five factors corresponding to the Big Five model of personality. The sixth factor, labelled Interpersonal Relationship Harmony, resembled the description of the Chinese tradition factor, extracted in a non-Western society.
\end{abstract}

\section{OPSOMMING}

Die wye aanvaarding van die Groot-Vyfmodel impliseer dat persoonlikheid uit relatief onafhanklike dimensies bestaan wat 'n taksonomie vorm waarmee individuele verskille verklaar kan word. Die doel van die ondersoek was om vas te stel of die subskale van 'n gevestigde persoonlikheidsvraelys wat gedetailleerde persoonlikheidstrekke meet, die Occupational Personality Questionnaire (OPQ), op sinvolle wyse gereduseer kon word tot 'n breë faktormodel in 'n Suid-Afrikaanse konteks. Die OPQ 5.2 konsepmodel is toegepas op 453 werkapplikante in die telekommunikasiesektor. 'n Ondersoekende faktorontleding het 'n sesfaktorstruktuur gelewer, insluitende vyf faktore wat met die Groot Vyf persoonlikheidsmodel ooreenstem. Die sesde faktor wat as Interpersoonlike Verhoudingsharmonie benoem is, toon ooreenstemming met die Chinese tradisiefaktor wat in 'n nie-Westerse samelewing onttrek is.

The utilisation of psychometric tests as part of the employment decision-making process provides a means for the expeditious and objective acquisition of information relating to employees or job applicants (Claassen, 1997; Foxcroft, 1997). During the past one and a half decades there has been a revival in the use of personality tests by industrial/organisational psychologists. In the years preceding the 1990s, personality tests were not held in high regard as personnel selection instruments, because it was believed that such tests do not demonstrate sufficient predictive validity when used to predict job performance criteria (Hurtz \& Donovan, 2000). However, the present increased popularity of personality measures can be ascribed to the various meta-analytical study outcomes that indicate that personality traits are effective predictors of employee performance and other behaviours in the workplace (Barrick \& Mount, 1991; Mount, Barrick \& Stewart, 1998; Ones \& Viswesvaran, 2001; Paunonen \& Ashton, 2001; Salgado, 1997; Van der Walt, Meiring, Rothman \& Barrick, 2002; Viswesvaran \& Ones, 2000) and also to the growing consensus amongst researchers that there exists a unifying model for explaining the structure of personality. For instance, several researchers have shown that a five-factor model of personality underlies some existing personality measuring instruments (Costa \& McCrae, 1992a; Digman, 1990, Goldberg, 1993) and that the general robustness of this so-called 'Big Five' model makes it a suitable platform for selection research (De Fruyt \& Furnham, 2000; Judge, Heller \& Mount, 2002).

Recent findings indicated that 37 percent of organisations in the United States of America make use of personality questionnaires in their employment programmes (Richman, Weisband, Kiesler \& Drasgow, 1999). It may be concluded that the use of personality questionnaires is prominent in the employment domain albeit controversial, a fact that the proliferation of research regarding the measurement of personality attests to (Barrett, Kline, Paltiel \& Eysenck, 1996; Craik, Hogan \& Wolfe, 1993; Ones \& Viswesvaran, 2001). The

Requests for copies should be addressed to: D Visser, Department of Human

Resource Management, RAU, PO Box 524, Auckland Park, 2006 users of personality tests in the work domain, namely industrial/organisational psychologists, do not represent the only group involved in the ongoing controversies, because the recipients of personality testing, namely employees and prospective employees, likewise have opinions about being assessed by such methods. The reactions of prospective job applicants who were requested to indicate their perceptions of the fairness of personality measures as selection instruments, indicated that some groups regarded personality tests as being relatively unfair compared to other selection methods (Steiner \& Gilliland, 1996; Visser \& De Jong, 2001).

One of the main problem areas currently occupying the efforts of personality researchers concerns the relative utility of broad factors, such as the factors included in the parsimonious description of personality proposed by the fivefactor model, as against measurements of personality comprising numerous factors or factors focusing on particular work outcomes (Hogan \& Roberts, 1996; Ones \& Viswesvaran 1996; Ones \& Viswesvaran, 2001; Paunonen \& Ashton, 2001; Stewart, 1999). Some researchers are of the opinion that narrow personality traits are effective predictors of job performance, because strong relationships with specific dimensions of job performance are demonstrated (Ashton, 1998; Hough, 1992).

Another point of view is that broad personality traits provide more potential to predict work performance across various professions (Murphy, 1989; Ones \& Viswesvaran, 1996; Schmidt \& Hunter, 1992; Stewart, 1999). For instance, Ones, Viswesvaran and Schmidt (1993) found that a linear combination of three of the Big Five dimensions, namely Conscientiousness, Agreeableness, and Emotional Stability, as measured by integrity tests, yielded higher predictive validity coefficients than any of the five factors separately. Similarly, Salgado (1999) reported that criterion-related validities for Big Five questionnaires are somewhat higher than those for general personality scales for adults regardless of their theoretical or empirical bases. 
Advocating the utility of broad personality traits, Ones and Viswesvaran (1996) further indicated that such traits are more reliable than narrow personality traits, because personality scales that measure the Big Five yield higher reliabilities than the narrow personality scales from which they originate. The mere fact that broad traits are typically measured by means of scales containing more items than scales measuring narrow traits, may of course offer an explanation for these findings. Nevertheless, Ashton (1998) argued that an increase in the reliability of broad personality scales does not necessarily suggest that they are better predictors of specific criteria than the narrow personality scales from which they derive. According to Ashton (1998), research should rather focus on whether there is an increase in the validity of the scales. The crucial question is therefore whether an increase in the reliability of broad personality scales result in increased validity that is higher than the validity of the narrow personality scales from which they are constituted.

Despite their earlier endorsement of broad factors, a recent metaanalysis by Ones and Viswesvaran (2001) questioned whether the Big Five predict job performance better than narrow and focused personality tests which they called criterion-focused occupational personality scales (COPS). They found that Conscientiousness and two of its facets predicted counterproductive job behaviours somewhat better than COPS, but that COPS produced superior validity coefficients compared to traditional Big Five measurements when supervisory ratings of job performance were being predicted. A consistent research finding has been that, among the Big Five dimensions, the highest criterion-related validities have been reported for Conscientiousness (Barrick \& Mount, 1991; Ones \& Viswesvaran, 1996; Salgado, 1997). It is interesting to note that Ones and Viswesvaran (2001) pointed out that all COPS examined so far have been related in varying degrees to three of the Big Five dimensions, namely Conscientiousness, Agreeableness and Emotional Stability.

One of the most important objections regarding the use of the five-factor model of personality is the presumed loss of information when narrow or detailed traits of personality are combined to reflect broad personality traits (Hough, 1992; Kanfer, Ackerman, Murtha \& Goff, 1996; Nyfield, 1994). Many practitioners appear to believe that narrow detailed measures of personality traits provide a focused understanding of personality and should therefore be preferred. They claim that they have to choose between the careful measurement of narrowly defined variables and more cursory measurements that combine the common variance contained in sets of narrow traits. The so-called bandwidth-fidelity dilemma that was first coined by Cronbach and Gleser (1965) deals, in the context of personality assessment, with whether it is preferable to measure broad personality traits than to measure narrowly defined traits when the objectives are to predict job performance and to understand behaviour. It should be kept in mind that the answer to the dilemma may differ, depending on which of the two objectives are pursued, and also on the specificity of the criteria to be predicted. Ones and Viswesvaran (1996) furthermore cautioned that broad traits do not by definition imply low fidelity assessment. They regard bandwidth and fidelity as separate issues, because it is conceivable that broad traits may involve high fidelity assessment. It appears that one's choice between measuring broad as opposed to narrow personality scales is determined by the following two considerations: (a) the nature of the phenomenon to be predicted or explained, and (b) if narrowly defined traits are to be used, whether the narrow constellation of personality traits can be operationally defined, so that they are conceptually and empirically independent of one another (Ashton, 1998; Ones \& Viswesvaran, 1996).

A common view of personality that appears to be consistent with the concepts of broad and narrowly defined personality traits, is that personality is hierarchically structured (Goldberg, 1993; McCrae \& John, 1992; Paunonen, 1998; Pervin, 1994). Constructs at the top of the hierarchy represent the broad factors that explain variance common to several of the narrow personality traits lower in the hierarchy (Paunonen, 1998; Stewart, 1999). For instance, Digman (1997) has shown that three of the Big Five dimensions, namely Conscientiousness, Agreeableness and Emotional Stability, correlate to form a higher order personality factor when multiple data sets are factor analysed. He has tentatively labelled this variable Factor Alpha and described it as the essence of the socialisation process. Constructs lower in the hierarchy are then identified by two components, namely a common component that is shared by some other narrow measures, and a specific component that is unique to the narrow measure in question (Costa \& McCrae, 1995). When several intercorrelated narrow traits are combined to form a broad trait, it happens that the measurement of the broad personality trait eliminates variance specific to the particular narrow traits in question, leaving only variance common to the constructs. Subsequently, measures of broad personality traits are more comprehensive and abstract. Narrow measurements of personality traits are therefore factorially more homogeneous than broad personality measurements (Ones \& Viswesvaran, 1996). The foregoing logic ties in neatly with the general structure of hierarchical theories and the methodology of factor analysis, so that the issue at stake appears merely to be a choice of the appropriate level of specificity.

The outcome of a hierarchical view of personality is that, in contrast with the robustness of common variance, the specific variance that is associated with each narrow personality trait is also associated with a relatively narrow behavioural pattern. As a result, a narrow personality trait may be an effective predictor of job performance, particularly if job performance is dependent on the behaviour associated with the specific variance of the trait in question (Hogan \& Roberts, 1996; Schneider, Hough \& Dunnette, 1996).

Personality questionnaires vary considerably with regard to the number of subscales of which they are composed (Barrick \& Mount, 1991; Briggs, 1989; Paunonen, 1998; Schmidt \& Ryan, 1993; Stewart, 1999). Some questionnaires focus on a number of broad, stable personality traits, whereas others measure numerous personality traits that are often interdependent and/or relatively unstable. Whenever traits are not independent of one another, a redundancy of scales occurs that makes it difficult to compare applicants in a selection context. When narrow personality traits are used to evaluate applicants, some process of combining traits must often take place to facilitate comparisons between applicants. As a result, extensive research is being carried out to find personality models that will aid such comparisons.

Cattell (1947) was one of the first researchers to develop a taxonomy for the classification of personality traits. His taxonomy consisted of sixteen primary factors and eight second-order factors (Cattell, Eber \& Tatsuoka, 1992). Fiske (1971) reanalysed Cattell's results, but he was able to find confirmation for only five of the second-order factors. In a separate study, Norman (1967) obtained similar results to Fiske, and his scale names for the five factors that became known as the Big Five, namely Extraversion, Emotional Stability, Agreeableness, Conscientiousness and Openness to Experience, are still commonly used. However, several researchers (Benet \& Waller, 1995; Deary, 1996; Jackson, Paunonen, Fraboni \& Goffin, 1996; Paunonen \& Jackson, 2000) suggested the existence of a sixth factor or even more factors. Benet and Waller (1995) referred to the sixth factor as the Emotional Dimension, although the content and labelling of this factor has led to an ongoing debate (Becker, 1999). Van de Vijver (2002) and Cheung and Leung (1998) indicated that a sixth factor is often found in research using samples in 
developing countries. It focuses on interpersonal relations and, more specifically, depicts Relationship Harmony. Ashton and Lee $(2001 ; 2002)$ also proposed a sixth factor that they labelled Honesty. McCrae and Costa (1995) as well as Saucier (2002) were, however, sceptical about the existence of more than five factors. They insisted that if such factors do exist, they must measure up to the following three criteria: (a) any new factor must be substantially independent of the other five factors (b) it must have a similar level of generalisability as the five factors, and (c) it must be relevant in more than one context. Becker (1999) claimed to have met the three criteria in his research and concluded that there was indeed a sixth factor that was labelled Spontaneity. In contrast, Saucier (2002) argued that the most likely sixth factor would be Negative Valence.

Recent research confirmed the robustness of the Big Five model across various theoretical frameworks (Becker, 1999; McAdams, 1992; McCrae, 1989; Miller, 1991; Saucier, 2002), various cultures (Barrick \& Mount, 1991; Ones, Viswesvaran \& Schmidt, 1993), different personality measuring instruments (Barrick \& Mount, 1991; McCrae \& Costa, 1989; McCrae, 1989) and a variety of samples (Barrick \& Mount, 1991; Digman, 1990). Despite widespread use across the globe of measuring instruments to assess the five-factor model, Cheung and Leung (1998), Cheung, Leung, Zhang, Sun, Gan, Song and Xie (2001), Laher and Leibowitz-Levy (2003) and Triandis and Suh (2002) cautioned that claims of the universality of the Big Five personality factors, are premature. They argued that most studies conducted in non-Western countries did not use samples that were culturally very different from Western samples, nor did they include culture-specific (emic) traits in their measuring instruments.

Nevertheless, a large body of research suggests that the fivefactor model of personality emerges in many countries (McCrae \& Costa, 1997; McCrae, Costa, Del Pilar, Rolland \& Parker, 1998). In South Africa four studies have investigated the applicability of the model for South African population groups, but these studies produced conflicting results. Heaven, Connors and Stones (1994) did not find support for a five-factor structure when they applied a measure consisting of a list of trait adjectives proposed by John (1990) to 200 Black South African students, nor did Heaven and Pretorius (1998) succeed in doing so when translations of the adjectives were administered to 247 Black Sotho-speaking students. However, the same procedure for a sample of 155 Afrikaansspeaking students yielded a five-factor structure in support of the Big Five model.

In another South African study, Van Eeden and Prinsloo (1997) factor analysed the Sixteen Personality Factor Questionnaire (16PF) subscale scores of job applicants in the banking sector and obtained a five-factor solution for the total group. However, when the scores of two subgroups, those whose first language was of European extraction and those with an African first language, were factor analysed separately, the solutions for the two subgroups differed in the number of factors and the nature of the factors that emerged. Nevertheless, three of the five factors did correspond for the two subgroups in this study.

In the fourth study, Heuchert, Parker, Stumpf and Myburgh (2000) administered the Revised NEO Personality Inventory (NEO-PI-R) to 408 students. When the students' facet scores were factor analysed, the structure of the fivefactor model was reproduced satisfactorily for the total sample as well as for the White and Black subgroups. The latter results indicated that the personality structure of Black and White South Africans are fairly similar, despite the fact that statistically significant differences in mean scores with regard to Openness to Experience were obtained between the subgroups.
Despite the popularity of the Big Five model, there is a great deal of debate concerning the precise meanings of its factors (Barrick \& Mount, 1991; Becker, 1999; Costa \& McCrae, 1995; McAdams, 1992; Pervin, 1994). The first factor is often referred to as Extraversion/ Introversion or Surgency (Ashton \& Lee, 2001; Costa \& McCrae, 1995; Hogan \& Hogan, 1989; McAdams, 1992; Stewart, 1999). The second factor is regarded as Emotional Stability, Stability, Emotional Condition or Neuroticism (McAdams, 1992; McCrae \& John, 1992; Pervin, 1994; Peterson, 1992). Personality traits often associated with the second factor are anxiety, depression, uncertainty, worry and emotion. The third factor is interpreted as Agreeableness, Compliancy or Obliging Tendency (Barrick \& Mount, 1991; Costa \& McCrae, 1995; McAdams, 1992; Peterson, 1992; Pervin, 1994). Hogan and Hogan (1989) and Digman (1990) referred to this factor as Friendliness. Although the fourth factor is often interpreted as Conscientiousness, it is also known as Perseverance and Will Power (Barrick \& Mount, 1991; Costa \& McCrae, 1995). The fifth factor, Openness to Experience, is also regularly interpreted as Intelligence or Intellect (McAdams, 1992; Peterson, 1992; Pervin, 1994). This factor is sometimes referred to as Culture or Experience (Hogan \& Hogan, 1989; McCrae \& Costa, 1989). The question arises why it has been so difficult to determine the meanings of the five factors. Rust and Golonbok (1994) argued that this was to some extent due to the statistical procedure, namely factor analysis, which is used for the development and justification of the five-factor model. Another reason is that the labelling of factors is determined by researchers' individual interpretations of the psychological meanings of the factors.

The widespread acceptance of the Big Five model has important implications for recruitment and selection. It implies that personality is comprised of relatively independent dimensions that form a taxonomy whereby individual differences may be classified and explained. The purpose of this study was to investigate whether an established personality questionnaire that measures narrow traits of personality, namely the Occupational Personality Questionnaire (OPQ), could be reduced meaningfully to fit a broad factor model (such as the Big Five model) within a South African context. Such a categorisation of subscales would only be meaningful if a clear and psychologically interpretable factor structure with relatively independent factors that also demonstrate high internal consistency, could be found. The OPQ is one of the most widely used personality questionnaires in South Africa within the work context. If it can be shown that the number of OPQ dimensions can be reduced to fit a parsimonious model of personality, it will lend support to the hierarchical view of personality and pave the way toward new possibilities for comparisons among individuals with regard to personnel decisions. The goal of the present study was therefore restricted to an examination of the underlying factor structure of the OPQ and an evaluation of the internal consistency reliabilities of the resulting factor scales. No attempt was made to evaluate the predictive validity of the broad factor scales in comparison with the narrow subscales of the OPQ.

\section{METHOD}

\section{Participants}

An accidental sample of 453 employees from a telecommunications organisation in the Gauteng province, South Africa was used. The participants were male applicants for first level supervisory jobs. Their ages varied from 25 to 46 years. With regard to educational qualifications, $73 \%$ had matriculated, 21\% had Grade 10, and $6 \%$ had obtained a tertiary national diploma. The sample consisted of 103 (23\%) Black, 102 (22\%) Coloured, 76 (17\%) Asian, and 172 (38\%) White respondents. 


\section{Measuring Instrument}

The concept model version of the Occupational Personality Questionnaire (OPQ) was used to evaluate individual behavioural preferences within the work context. It is a personality questionnaire that consists of 30 substantive subscales and a social desirability scale (Saville, Holdsworth, Nyfield, Cramp \& Mabey, 1984). The subscales measure aspects of behaviour that are associated with interpersonal relationships, various thought styles, feelings and emotions. The concept model was constructed using the 'Repertory Grid', critical incidents and literature review methods, with the result that the questionnaire scales are based on deductive rather than inductive methods.

The two most detailed versions of the concept model of the OPQ are the Occupational Personality Questionnaire 5,2, a normative measuring instrument, and the Occupational Personality Questionnaire 4,2, an ipsative measuring instrument. It was decided to use the OPQ CM 5,2 concept model version in the present study, because the normative nature of the instrument allows for direct comparisons between individuals as well as statistical analyses such as factor analysis. The developers performed item analyses to ensure that the scales were reliable and that they do not correlate too highly with one another. The OPQ CM 5,2 consists of 248 items, eight items per subscale (Saville \& Holdsworth, 1993).

The utility of the OPQ CM 5,2 is supported by reports of its criterion-related validity and adequate reliability. To determine the reliability of the questionnaire, the developers of the instrument, Saville and Holdsworth (1993) applied the questionnaire to 2987 respondents. Cronbach alpha coefficients were obtained for the subscales and these varied between 0,57 and 0,88 . In two South African studies the so-called UK version of the OPQ CM 5.2 that was also used in the present study, yielded reliability coefficients that ranged from 0,28 to 0,82 (Saville \& Holdsworth Ltd. (South Africa), 2003a; 2003b). It is important to keep in mind that the version of the OPQ CM 5,2 used in the present study was the original British questionnaire. It later underwent particular item adjustments to make the questionnaire more suitable for South African conditions. The South African version of the OPQ CM 5,2 was administered to 161 employees from mixed industry sectors and yielded higher alpha coefficients ranging from 0,61 to 0,88 (Saville \& Holdsworth Ltd. (South Africa), 2003c).

The construct validity of the OPQ CM 5.2 was determined by means of factor analysis (Robertson \& Kinder, 1993; Saville \& Holdsworth, 1993; Saville \& Wilson, 1991). The results indicated that the personality subscales were substantially intercorrelated.

A new OPQ version that was developed internationally and adapted for use also in South Africa since the collection of the data for the present study, namely the OPQ 32n, yielded alpha coefficients for a British sample ranging from 0,63 to 0,87 for its 32 subscales (Saville \& Holdsworth, 1999). Satisfactory internal consistency reliabilities were also found for a South African sample (Saville \& Holdsworth Ltd. (South Africa), 2003d) consisting of 1181 employees and students from a variety of industry sectors. The alpha coefficients for the various subscales ranged from 0,71 to 0,89 .

\section{Procedure}

All the psychometric assessments were completed in standardised circumstances under the guidance of trained psychometrists. The collection of the data was completed within

TABLE 1

OPQ SCALES USED TO REFLECT THE SCALES OF THE FIVE-FACTOR MODEL

\begin{tabular}{|c|c|c|c|}
\hline Five-factor model & OPQ scales (1) & OPQ scales (2) & OPQ scales (3) \\
\hline Openness to Experience & $\begin{array}{l}\text { T7 (Conceptual) } \\
\text { T3 (Artistic) } \\
\text { T4 (Behavioural) } \\
\text { T8 (Innovative) }\end{array}$ & $\begin{array}{l}\text { T8 (Innovative) } \\
\text { T3 (Artistic) } \\
\text { T4 (Behavioural) } \\
\text { R3 (Independent) }\end{array}$ & $\begin{array}{l}\text { T4 (Behavioural) } \\
\text { T3 (Artistic) } \\
\text { T8 (Innovative) } \\
\text { T7 (Conceptual) } \\
\text { T5 (Traditional)* }{ }^{*}-\text { ) } \\
\text { T2 (Data Rational)* }\end{array}$ \\
\hline Agreeableness & $\begin{array}{l}\text { R9 (Caring) } \\
\text { R8 (Democratic) } \\
\text { F8 (Competitive) (-) }\end{array}$ & $\begin{array}{l}\text { F8 (Competitive) (-) } \\
\text { R9 (Caring) } \\
\text { R8 (Democratic) } \\
\text { F9 (Achieving) (-) } \\
\text { F6 (Critical) (-) } \\
\text { R7 (Modest) } \\
\text { R3 (Independent) (-) }\end{array}$ & $\begin{array}{l}\text { F8 (Competitive) (-) } \\
\text { R9 (Caring) } \\
\text { R8 (Democratic) } \\
\text { F6 (Critical) (-) } \\
\text { R7 (Modest) } \\
\text { R3 (Independent) (-) } \\
\text { R2 (Controlling)* (-) } \\
\text { F10 (Decisive)* }{ }^{*}(-)\end{array}$ \\
\hline Conscientiousness & $\begin{array}{l}\text { T10 (Detail Conscious) } \\
\text { T11 (Conscientious) } \\
\text { T9 (Forward Planning) }\end{array}$ & $\begin{array}{l}\text { T10 (Detail Conscious) } \\
\text { T9 (Forward Planning) } \\
\text { T11 (Conscientious) } \\
\text { D1 (Socially Desirable) }\end{array}$ & $\begin{array}{l}\text { T10 (Detail Conscious) } \\
\text { T9 (Forward Planning) } \\
\text { T11 (Conscientious) } \\
\text { D1 (Socially Desirable) } \\
\text { F9 (Achieving)* }\end{array}$ \\
\hline Extraversion & $\begin{array}{l}\text { R4 (Outgoing) } \\
\text { R5 (Affiliative) } \\
\text { F4 (Emotional Control) (-) }\end{array}$ & $\begin{array}{l}\text { R4 (Outgoing) } \\
\text { R5 (Affiliative) } \\
\text { R6 (Socially confident) } \\
\text { R2 (Controlling) } \\
\text { F4 (Emotional Control) (-) }\end{array}$ & $\begin{array}{l}\text { R4 (Outgoing) } \\
\text { R5 (Affiliative) } \\
\text { F4 (Emotional Control) (-) } \\
\text { R6 (Socially confident) }\end{array}$ \\
\hline Emotional Stability & $\begin{array}{l}\text { F1 (Relaxed) } \\
\text { F2 (Worrying) (-) } \\
\text { F3 (Tough Minded) } \\
\text { F5 (Optimistic) }\end{array}$ & $\begin{array}{l}\text { F1 (Relaxed) } \\
\text { F2 (Worrying) (-) } \\
\text { F3 (Tough Minded) } \\
\text { F5 (Optimistic) }\end{array}$ & $\begin{array}{l}\text { F1 (Relaxed) } \\
\text { F2 (Worrying) (-) } \\
\text { F3 (Tough Minded) } \\
\text { F5 (Optimistic) }\end{array}$ \\
\hline
\end{tabular}

(1) Nyfield et al. (1995)

(2) Matthews et al. (1990)

(3) Assignment of OPQ scales to the five-factor model on logical grounds by the authors

* OPQ scales that were assigned to the five-factor model on logical grounds, but were not suggested by the Nyfield et al. (1995) and Matthews et al. (1990) studies

(-) OPQ scales for which a high score is associated with a low score on the factor 
a period of three months. The candidates were informed about the purpose of the session prior to the administration of the OPQ CM 5,2.

\section{RESULTS}

Nyfield, Gibbons, Baron and Robertson (1995) categorised the various OPQ subscales on the basis of a literature study and the results of a previous factor analysis of the OPQ, to reflect the construct definitions of the Big Five model of personality. Matthews, Stanton, Graham and Brimelow (1990) used factor analysis to extract those factors that had eigenvalues greater than unity. Their findings were subsequently compared with the construct definitions of the five-factor model, as reflected in the literature (McCrae \& Costa, 1989). The relevant information is provided in Table 1 . The purpose of Table 1 was to provide a framework against which the goodness of fit between the factors of the Big Five model and second level factors of the OPQ might be judged. The 31 OPQ scale definitions were subsequently studied and compared with the construct definitions of the five-factor model as reported by Nyfield et al. (1995) and Matthews et al. (1990). This was done to determine the extent to which a conceptual analysis would point to similarities between the personality scales of the OPQ and the five-factor model. The fourth column in Table 1 indicates the results of this argumentation. This column represents a hypothesised five-factor model and spells out the a priori expectations of the results of a factor analysis. The personality scales that are indicated with an asterisk in the fourth column of Table 1 are those OPQ scales that were assigned to the five-factor model on the basis of the conceptual analysis, but without support from the existing literature. The minuses indicate OPQ scales for which high scores are associated with low scores on the factor.

It is important to note that the aim of the conceptual analysis was not to provide a framework for confirmatory factor analysis. The analysis was done to facilitate the interpretation of possible observed factors that correspond with the factors in the Big Five model. It was decided to use exploratory factor analysis for determining the underlying factor structure of the OPQ subscales, because there were no specific expectations regarding the number or nature of the factors to be extracted.

Descriptive statistics for the respondents' raw scores on the 31 subscales of the OPQ are given in Table 2. For every scale the mean, standard deviation, minimum and maximum scores, and Cronbach's coefficient alpha (coefficient of internal consistency) are reported. The alpha coefficients for the 31 scales ranged from 0,31 to 0,83 . Nineteen of the OPQ CM 5,2 scales yielded internal consistency reliabilities higher than 0,60 . These results indicate that this early version of the OPQ contained several scales that did not measure 'pure' traits or that such scales measured more than one trait and may be correlated. The fact that the version of the OPQ CM 5,2 used in the present study was the original UK questionnaire probably contributed to the less than satisfactory reliabilities obtained for some subscales. Subsequent item adjustments for South African samples and a new version of the OPQ lead to higher internal consistency reliabilities (Saville \& Holdsworth Ltd. (South Africa), 2003c; 2003d).

It was decided to carry out an exploratory factor analysis using the respondents' total scores on the $31 \mathrm{OPQ}$ scales as input to determine whether the underlying factor structure of the OPQ resembled a Big Five factor model. Before proceeding, it was necessary to determine whether the sample was adequate for performing such an analysis. It was also necessary to establish whether there were a sufficient number of substantial correlations between the OPQ scales to merit a factor analysis.
The Kaiser-Meyer-Olkin measure of sampling adequacy (MSA) was equal to 0,89 and this was regarded as adequate for carrying out a factor analysis. Bartlett's test of sphericity yielded a statistically significant approximate chi-square $[\chi 2(465)=4430,90, p<0,001]$. The aforementioned diagnostic tests provided sufficient justification to perform the factor analysis.

TABLE 2

DESCRIPTIVE STATISTICS AND INTERNAL CONSISTENCY RELIABILITY COEFFICIENTS OF THE 31 OPQ SCALES $(\mathbf{N}=\mathbf{4 5 3})$

\begin{tabular}{lccccc}
\hline OPQ scale & M & SD & Minimum & Maximum & $\begin{array}{c}\text { Cronbach } \\
\text { alpha }\end{array}$ \\
\hline R1 (Persuasive) & 28,71 & 4,73 & 11,00 & 40,00 & 0,72 \\
R2 (Controlling) & 30,03 & 4,50 & 11,00 & 40,00 & 0,73 \\
R3 (Independent) & 29,66 & 3,45 & 20,00 & 40,00 & 0,38 \\
R4 (Outgoing) & 27,29 & 4,74 & 12,00 & 39,00 & 0,69 \\
R5 (Affiliative) & 30,51 & 3,67 & 16,00 & 40,00 & 0,51 \\
R6 (Socially confident) & 29,82 & 4,63 & 16,00 & 40,00 & 0,74 \\
R7 (Modest) & 23,07 & 5,15 & 11,00 & 36,00 & 0,74 \\
R8 (Democratic) & 30,29 & 4,09 & 18,00 & 40,00 & 0,60 \\
R9 (Caring) & 31,89 & 3,37 & 20,00 & 40,00 & 0,61 \\
T1 (Practical) & 31,74 & 4,96 & 9,00 & 40,00 & 0,83 \\
T2 (Data Rational) & 29,08 & 5,37 & 11,00 & 40,00 & 0,84 \\
T3 (Artistic) & 27,24 & 5,16 & 13,00 & 39,00 & 0,78 \\
T4 (Behavioural) & 30,03 & 3,25 & 20,00 & 40,00 & 0,48 \\
T5 (Traditional) & 21,37 & 3,86 & 10,00 & 35,00 & 0,49 \\
T6 (Change orientated) & 29,30 & 3,65 & 16,00 & 38,00 & 0,52 \\
T7 (Conceptual) & 27,46 & 3,74 & 16,00 & 38,00 & 0,52 \\
T8 (Innovative) & 30,16 & 4,45 & 16,00 & 40,00 & 0,74 \\
T9 (Forward planning) & 30,45 & 3,51 & 18,00 & 39,00 & 0,59 \\
T10 (Detail conscious) & 32,42 & 3,63 & 16,00 & 40,00 & 0,64 \\
T11 (Conscientious) & 33,42 & 3,55 & 21,00 & 40,00 & 0,56 \\
F1 Relaxed) & 27,87 & 4,45 & 15,00 & 40,00 & 0,67 \\
F2 (Worrying) & 25,37 & 4,09 & 11,00 & 36,00 & 0,52 \\
F3 (Tough minded) & 24,97 & 4,94 & 9,00 & 39,00 & 0,71 \\
F4 (Emotional control) & 22,76 & 4,84 & 8,00 & 35,00 & 0,69 \\
F5 (Optimistic) & 31,28 & 4,41 & 12,00 & 40,00 & 0,67 \\
F6 (Critical) & 28,23 & 3,79 & 13,00 & 40,00 & 0,54 \\
F7 (Active) & 29,18 & 4,69 & 10,00 & 40,00 & 0,71 \\
F8 (Competitive) & 22,28 & 4,36 & 13,00 & 37,00 & 0,59 \\
F9 (Achieving) & 28,84 & 3,46 & 17,00 & 39,00 & 0,31 \\
F10 (Decisive) & 23,72 & 4,50 & 12,00 & 39,00 & 0,64 \\
D1 (Social desirability) & 25,89 & 4,45 & 16,00 & 39,00 & 0,68 \\
\hline & & & & & \\
\hline
\end{tabular}

A principal axis factor analysis followed by a direct oblimin rotation of the axes to simple structure was subsequently performed on the total scores of the respondents on the OPQ scales. Using the conventional eigenvalue greater-than-one criterion, eight factors were extracted. Not all of the factors could be interpreted unambiguously. Furthermore, three of the eight factors had only two or three high factor loadings and were therefore poorly determined. Subsequently, a fivefactor structure was specified and thereafter also a six-factor structure. After studying the scree plots and considering the psychological interpretability of the obtained factors, it was decided to accept the six-factor model that explained 51,62\% of the variance. The factor pattern matrix of the OPQ is given in Table 3.

Cronbach alpha coefficients were determined for each of the obtained factors after scales with negative factor loadings were reverse scored. In Table 4 the intercorrelations between the six OPQ factors and their respective alpha coefficients are reported. The six factors reported in Table 3 were subsequently labelled in accordance with their psychological meaning and their correspondence to Big Five factors. (See 
also Tables 5 and 6 below for more information.) Factors 2, 3, 4 and 6 were reflected so that a high score on each of these factors would be associated with a high score on the variable in question. The correlations reported in Table 4 represent the correlations after Factors 2, 3, 4 and 6 were reflected. The alpha coefficients varied from 0,74 (Factor 4 labelled Agreeableness) to 0,86 (Factor 5 labelled Openness to Experience). With the exception of the Agreeableness scale, all the alpha coefficients exceeded 0,80. The correlation between Factor 5: Openness to Experience and Factor 6: Conscientiousness was the highest and was equal to 0,39 . The absolute values of the remaining intercorrelations were substantially lower and varied between 0,29 (Factor 1: Interpersonal and Factor 3: Emotional Stability) and 0,06 (Factor 2: Extraversion and Factor 6: Conscientiousness). Although the six OPQ factors were essentially independent of one another, there remained some degree of overlap between them. However, the intercorrelations were relatively low and in all instances they were lower than the reliability coefficients of the factors.

TABLE 3

FACTOR PATTERN MATRIX OF THE OPQ SCALE SCORES

\begin{tabular}{|c|c|c|c|c|c|c|c|}
\hline \multirow[t]{2}{*}{ OPQ scale } & \multicolumn{6}{|c|}{ Factors } & \multirow[t]{2}{*}{$h^{2}$} \\
\hline & 1 & 2 & 3 & 4 & 5 & 6 & \\
\hline T4 (Behavioural) & $\underline{0,69}$ & 0,07 & 0,12 & 0,05 & 0,22 & $-0,06$ & 0,58 \\
\hline R9 (Caring) & $\underline{0,49}$ & 0,08 & 0,06 & $-0,12$ & 0,06 & $-0,23$ & 0,36 \\
\hline R5 (Affiliative) & $\underline{0,47}$ & $-0,16$ & $-0,24$ & $-0,04$ & $-0,03$ & 0,06 & 0,37 \\
\hline F5 (Optimistic) & $\underline{0,38}$ & 0,01 & $\underline{-0,34}$ & 0,09 & $-0,02$ & $-0,23$ & 0,48 \\
\hline T6 (Change orientated) & $\underline{0,32}$ & $-0,12$ & $-0,13$ & 0,06 & 0,21 & $-0,14$ & 0,37 \\
\hline F4 (Emotional control) & $-0,04$ & $\underline{0,63}$ & 0,01 & 0,15 & 0,00 & $-0,02$ & 0,39 \\
\hline R7 (Modest) & 0,16 & $\underline{0,57}$ & $-0,12$ & $-0,02$ & 0,01 & $-0,04$ & 0,33 \\
\hline R4 (Outgoing) & 0,29 & $-\underline{0,38}$ & $-\underline{0,32}$ & 0,26 & $-0,06$ & 0,07 & 0,55 \\
\hline R1 (Persuasive) & 0,22 & $\underline{-0,32}$ & $-0,16$ & 0,22 & 0,03 & $-0,23$ & 0,48 \\
\hline F7 (Active) & 0,10 & $-0,17$ & $-0,15$ & $-0,04$ & 0,17 & $-0,08$ & 0,17 \\
\hline F1 (Relaxed) & 0,12 & 0,23 & $\underline{-0,70}$ & 0,08 & 0,03 & $-0,12$ & 0,63 \\
\hline F2 (Worrying) & 0,11 & 0,05 & $\underline{0,67}$ & $-0,12$ & $-0,09$ & $-0,11$ & 0,47 \\
\hline F3 (Tough minded) & $-0,05$ & $-0,01$ & $\underline{-0,64}$ & $-0,17$ & 0,09 & 0,00 & 0,44 \\
\hline R6 (Socially confident) & 0,24 & $-0,23$ & $\underline{-0,52}$ & 0,22 & $-0,02$ & $-0,08$ & 0,65 \\
\hline T5 (Traditional) & $-0,11$ & 0,04 & 0,24 & $-0,09$ & 0,00 & 0,15 & 0,16 \\
\hline F10 (Decisive) & 0,01 & 0,07 & $-0,03$ & $\underline{0,64}$ & 0,10 & $-0,01$ & 0,42 \\
\hline R8 (Democratic) & 0,29 & $-0,07$ & $-0,02$ & $\underline{-0,53}$ & 0,25 & $-0,05$ & 0,44 \\
\hline R2 (Controlling) & 0,15 & $-0,19$ & $-0,04$ & $\underline{0,41}$ & 0,15 & $\underline{-0,31}$ & 0,57 \\
\hline R3 (Independent) & 0,27 & $-0,05$ & $-0,05$ & $\underline{0,32}$ & 0,13 & $-0,16$ & 0,36 \\
\hline T7 (Conceptual) & 0,12 & $-0,01$ & $-0,01$ & 0,17 & $\underline{0,61}$ & 0,13 & 0,43 \\
\hline T2 (Data rational) & $-0,07$ & $-0,02$ & $-0,12$ & $-0,01$ & $\underline{0,49}$ & $-0,20$ & 0,40 \\
\hline T3 (Artistic) & 0,04 & 0,00 & $-0,15$ & $-0,02$ & $\underline{0,48}$ & 0,18 & 0,25 \\
\hline T8 (Innovative) & 0,12 & $-0,17$ & $-0,15$ & 0,13 & $\underline{0,38}$ & $-0,16$ & 0,48 \\
\hline F6 (Critical) & 0,18 & $-0,09$ & $-0,02$ & $-0,03$ & $\underline{0,31}$ & $-0,15$ & 0,27 \\
\hline T1 (Practical) & $-0,03$ & 0,01 & 0,08 & $-0,07$ & 0,27 & $-0,16$ & 0,11 \\
\hline F8 (Competitive) & $-0,19$ & $-0,14$ & 0,05 & 0,18 & 0,21 & $-0,19$ & 0,19 \\
\hline T11 (Conscientious) & 0,23 & 0,04 & 0,03 & 0,09 & $-0,05$ & $\underline{-0,68}$ & 0,57 \\
\hline T10 (Detail conscious) & 0,10 & 0,03 & $-0,05$ & 0,02 & $-0,01$ & $\underline{-0,62}$ & 0,43 \\
\hline T9 (Forward planning) & 0,21 & $-0,07$ & $-0,11$ & $-0,02$ & 0,27 & $\underline{-0,43}$ & 0,55 \\
\hline $\begin{array}{l}\text { D1 (Social desirability } \\
\text { response) }\end{array}$ & $-0,19$ & 0,11 & $\underline{-0,36}$ & $-0,17$ & 0,03 & $\underline{-0,40}$ & 0,34 \\
\hline F9 (Achieving) & $-0,04$ & $-0,08$ & $-0,04$ & 0,17 & 0,16 & $-0,40$ & 0,31 \\
\hline
\end{tabular}

Factor loadings $\geq 0,30$ indicated in bold are regarded as an indication of the variables which best define the relevant factor

A summary of the six-factor model with factor labels is provided in Table 5. Each factor contains several substantial factor loadings represented by the OPQ scales. All of the factors were well determined, because at least four OPQ scales loaded on each of them
TABLE 4

InTERCorrelations OF THE OPQ FACTORS AND Cronbach ALPHA COEFFICIENTS OF THE FACTORS

\begin{tabular}{lccccccc}
\hline Factors & 1 & 2 & 3 & 4 & 5 & 6 & $\begin{array}{c}\text { Cronbach } \\
\text { alpha } \\
\text { coefficients }\end{array}$ \\
\hline 1 & 1,00 & & & & & & 0,81 \\
2 & 0,17 & 1,00 & & & & & 0,82 \\
3 & 0,29 & 0,15 & 1,00 & & & & 0,84 \\
4 & $-0,08$ & $-0,22$ & $-0,13$ & 1,00 & & & 0,74 \\
5 & 0,28 & 0,27 & 0,28 & $-0,12$ & 1,00 & & 0,86 \\
6 & 0,26 & 0,06 & 0,24 & $-0,13$ & 0,39 & 1,00 & 0,81 \\
\hline
\end{tabular}

In order to interpret the six OPQ factors and to establish the extent to which the obtained factors resembled Big Five factors, the descriptions of the OPQ scales in the questionnaire manual (Saville \& Holdsworth, 1993) that had high loadings on each factor, were studied. The factors were labelled accordingly and labels ordinarily given to the Big Five factors were used where appropriate (see Tables 5 and 6) In Table 6 a summary of the scale descriptions are provided in most cases including descriptions of the meanings of obtaining both high and low scores on the respective factors. In cases where negative loadings (i.e. low scores on the factors) were obtained, the descriptions of the OPQ scales associated with the negative loadings were used to indicate meanings at the opposite poles of the factor continua. For purposes of comparison, summary descriptions of the Revised NEO Personality Inventory factors (NEO-PI-R) (Costa \& McCrae, 1992b) with corresponding labels are also provided in Table 6.

Finally, three factor solutions were tested by carrying out rotations to partially specified targets using the TARROT program developed by Browne (1972a, 1972b). (See also Browne, Cudeck, Tateneni \& Mels, 1998.) The models tested were the obtained six-factor solution, the hypothesised fivefactor model proposed in Table 1 , and a Big Five solution reported by Saville and Holdsworth (1999) in using the OPQ $32 \mathrm{n}$ on a British sample.

To test the six-factor solution, the unrotated factor matrix, obtained by a principal axis factor analysis, served as the input matrix. A target matrix of the same dimensions as the factor matrix was constructed by placing zeros where loadings were expected to be small and nines where loadings were expected to be substantial. Oblique rotation to the specified target was subsequently carried out and the resulting TARROT rotated factor pattern matrix was examined to determine its correspondence with the solution presented in Table 3. Because this procedure was akin to a replication of the exploratory factor analysis carried out before, it was hardly surprising that the new pattern matrix closely resembled the one obtained earlier. The factor loadings of the new pattern matrix differed only in the second decimal from the matrix reported in Table 3 . The sizes of the differences between the two sets of loadings defining the various factors ranged between zero and 0,05 . The obtained TARROT pattern matrix is therefore not reported in a table.

The next model to be rotated to a specified target was the five-factor model proposed in Table 1 . The same procedure as described above was carried out, but this time a target matrix, specifying five factors and using the subscales listed in the fourth column of Table 1 to indicate the expected factor loadings for the five factors, was constructed. The TARROT pattern matrix for the hypothesised model is reported in Table 7. As with the previous model, convergence was attained. The data appeared to fit the hypothesised model rather well, because 21 of the 27 expected loadings were equal to or larger than 0,30 . However, there were eight subscales 
TABLE 5

SUMMARY OF SUBSCALES WITH HIGH LOADINGS ON THE SIX-FACTOR MODEL

\begin{tabular}{|c|c|c|c|c|c|}
\hline Interpersonal & Extraversion & Emotional stability & Agreeableness & Openness to experience & Conscientiousness \\
\hline $\begin{array}{l}\text { Behavioural } \\
(0,69)\end{array}$ & $\begin{array}{l}\text { Emotional control } \\
(-0,63)\end{array}$ & $\begin{array}{l}\text { Relaxed } \\
(0,70)\end{array}$ & $\begin{array}{l}\text { Decisive } \\
(-0,64)\end{array}$ & $\begin{array}{l}\text { Conceptual } \\
(0,61)\end{array}$ & $\begin{array}{l}\text { Conscientious } \\
(0,68)\end{array}$ \\
\hline $\begin{array}{l}\text { Caring } \\
(0,49)\end{array}$ & $\begin{array}{l}\text { Modest } \\
(-0,57)\end{array}$ & $\begin{array}{l}\text { Worrying } \\
(-0,67)\end{array}$ & $\begin{array}{l}\text { Democratic } \\
(0,53)\end{array}$ & $\begin{array}{l}\text { Data rational } \\
(0,49)\end{array}$ & $\begin{array}{l}\text { Detail conscious } \\
(0,62)\end{array}$ \\
\hline $\begin{array}{l}\text { Affiliative } \\
(0,47)\end{array}$ & $\begin{array}{l}\text { Outgoing } \\
(0,38)\end{array}$ & $\begin{array}{l}\text { Tough minded } \\
(0,64)\end{array}$ & $\begin{array}{l}\text { Controlling } \\
(-0,41)\end{array}$ & $\begin{array}{l}\text { Artistic } \\
(0,48)\end{array}$ & $\begin{array}{l}\text { Forward planning } \\
(0,43)\end{array}$ \\
\hline $\begin{array}{l}\text { Optimistic } \\
(0,38)\end{array}$ & $\begin{array}{l}\text { Persuasive } \\
(0,32)\end{array}$ & $\begin{array}{l}\text { Socially confident } \\
(0,52)\end{array}$ & $\begin{array}{l}\text { Independent } \\
(-0,32)\end{array}$ & $\begin{array}{l}\text { Innovative } \\
(0,38)\end{array}$ & $\begin{array}{l}\text { Social desirability } \\
(0,40)\end{array}$ \\
\hline \multirow[t]{3}{*}{$\begin{array}{l}\text { Change orientated } \\
(0,32)\end{array}$} & & $\begin{array}{l}\text { Social desirability } \\
(0,36)\end{array}$ & & $\begin{array}{l}\text { Critical } \\
(0,31)\end{array}$ & $\begin{array}{l}\text { Achieving } \\
(0,40)\end{array}$ \\
\hline & & $\begin{array}{l}\text { Optimistic } \\
(0,34)\end{array}$ & & & $\begin{array}{l}\text { Controlling } \\
(0,31)\end{array}$ \\
\hline & & $\begin{array}{l}\text { Outgoing } \\
(0,32)\end{array}$ & & & \\
\hline
\end{tabular}

TABLE 6

DESCRIPTIONS OF THE OPQ CM 5.2 FACTORS AND NEO-PI-R SUBSCALES

\begin{tabular}{ll}
\hline Factor & OPQ description \\
\hline $\begin{array}{l}\text { Interpersonal (relationship harmony) } \\
\text { High score }\end{array}$ & $\begin{array}{l}\text { Analyses behaviour of others, psychologically minded, } \\
\text { considerate, caring, tolerant, shares with others, } \\
\text { sympathetic, likes companionship of friends, values } \\
\text { friendship, helps others, optimistic }\end{array}$
\end{tabular}

\section{Extraversion}

High score

Low score

Emotional stability (versus neuroticism)

High score

Low score

Agreeableness

High score

Low score

Openness to experience

High score

Low score

\section{Conscientiousness}

High score

Low score
Sociable, talkative, vibrant, fun loving, jovial, persuasive

Avoids talking about self, restrained in showing emotions, reserved about achievements

Calm, relaxed, cool under pressure, free from anxiety, not easily hurt or upset, socially confident, cheerful despite setbacks

Worries when things go wrong, copes poorly with stress, anxious to do well

Democratic, consults, listens to others, encourages others to contribute

Decisive, draws quick conclusions, controlling, takes charge, outspoken, expresses strong views

Intellectual curiosity, conceptual thinking, enjoys complex and abstract thinking, enjoys assessing facts, artistic, innovative, creative, evaluative perseveres, methodical, precise, accurate, plans an prepares in advance, achieving, results orientated, ambitious
NEO-PI-R description

Sociable, assertive, active, talkative, likes excitement, energetic, optimistic

Reserved, independent, prefers to be alone, do not suffer social anxiety, not unhappy or pessimistic

Adjustment, emotionally stable, calm, even-tempered, relaxed

Maladjustment, tendency to experience negative affects, copes poorly with stress

Altruistic, eager to help others, sympathetic to others, cooperative

Egocentric, sceptical, competitive, fights for own interests

Imagination, aesthetic, intellectual curiosity, independent judgement, unconventional, novel ideas, intellect, creative, willing to question authority

Conventional, conservative, prefer the familiar, narrower interests

Purposeful, strong-willed, determined, carries out tasks, plans activities, achieving, compulsive or workaholic behaviour, scrupulous, punctual, reliable, conscientious

Lackadaisical regarding goals that yielded factorially complex loadings in the pattern matrix and 16 loadings equal to or larger than 0,30 that were not specified. In particular, the Conscientiousness and Extraversion dimensions were not clearly differentiated, because loadings larger than 0,30 were obtained on both dimensions for three subscales.

For the third model, a Big Five solution, obtained for 2028 British respondents with the British version of the OPQ 32n (Saville \&
Holsworth, 1999), was used to construct the target matrix. For the TARROT procedure the unrotated factor matrix obtained by a principal components analysis of the OPQ CM 5,2 subscale totals, rather than a principal axis factor analysis, served as the input matrix in this instance. This was done for consistency, because this was the procedure followed by SHL (Saville \& Holdsworth, 1999). The rotated factor pattern matrix is presented in Table 8 . In the revision of the OPQ from the concept model to the $32 \mathrm{n}$, a small number of new subscales were added. These scales were not 
included in the target rotation, but scales that were restructured or adapted (and/or given new names) were evaluated against the concept model scales from which they originated.

TABLE 7

ROTATED FACTOR PATTERN MATRIX FOR THE HYPOTHESISED MODEL USING TARROT TARGET ROTATION

\begin{tabular}{|c|c|c|c|c|c|}
\hline $\begin{array}{l}\text { OPQ } \\
\text { scale }\end{array}$ & Openness & Agreeableness & $\begin{array}{c}\text { Factors } \\
\text { Conscientiousness }\end{array}$ & Extraversion & Neuroticism \\
\hline $\mathrm{T} 4$ & 0,06 & $-0,17$ & $\underline{0,37}$ & $\underline{0,49}$ & $-0,12$ \\
\hline R9 & 0,00 & $-0,25$ & $\underline{0,43}$ & 0,29 & $-0,05$ \\
\hline R5 & 0,00 & $-0,15$ & $-0,02$ & $\underline{0,57}$ & 0,18 \\
\hline F5 & $-0,05$ & $-0,01$ & 0,32 & $\underline{0,34}$ & $\underline{0,32}$ \\
\hline T6 & 0,22 & 0,01 & 0,12 & $\underline{0,32}$ & 0,09 \\
\hline $\mathrm{F} 4$ & $\underline{-0,35}$ & $-0,04$ & 0,29 & $\underline{-0,33}$ & 0,09 \\
\hline R7 & $-0,29$ & $-0,23$ & $\underline{0,33}$ & $-0,15$ & 0,21 \\
\hline R4 & 0,06 & 0,25 & $-0,17$ & $\underline{0,60}$ & 0,20 \\
\hline R1 & 0,17 & 0,27 & 0,15 & $\underline{0,36}$ & 0,07 \\
\hline F7 & 0,27 & $-0,02$ & 0,04 & 0,16 & 0,11 \\
\hline F1 & $-0,10$ & $-0,03$ & 0,21 & 0,08 & $\underline{0,71}$ \\
\hline $\mathrm{F} 2$ & $-0,09$ & $-0,13$ & 0,20 & $-0,10$ & $\underline{-0,62}$ \\
\hline F3 & 0,16 & $-0,15$ & $-0,09$ & 0,04 & $\underline{0,63}$ \\
\hline R6 & 0,06 & 0,20 & 0,02 & $\underline{0,45}$ & $\underline{0,43}$ \\
\hline T5 & $-0,02$ & $-0,08$ & $-0,15$ & $-0,13$ & $-0,22$ \\
\hline F10 & $-0,10$ & $\underline{0,53}$ & 0,14 & 0,09 & 0,00 \\
\hline R8 & $\underline{0,37}$ & $-\underline{0,57}$ & 0,09 & 0,17 & 0,03 \\
\hline $\mathrm{R} 2$ & 0,17 & $\underline{0,44}$ & 0,33 & 0,20 & $-0,02$ \\
\hline R3 & 0,05 & 0,25 & 0,28 & 0,27 & 0,01 \\
\hline $\mathrm{T} 7$ & $\underline{0,40}$ & 0,10 & 0,09 & 0,15 & 0,01 \\
\hline $\mathrm{T} 2$ & $\underline{0,48}$ & 0,03 & 0,25 & $-0,14$ & 0,14 \\
\hline T3 & $\underline{0,36}$ & $-0,06$ & $-0,05$ & 0,09 & 0,14 \\
\hline $\mathrm{T} 8$ & $\underline{0,41}$ & 0,15 & 0,20 & 0,17 & 0,11 \\
\hline F6 & $\underline{0,33}$ & $-0,04$ & 0,22 & 0,13 & 0,01 \\
\hline $\mathrm{T} 1$ & 0,29 & $-0,04$ & 0,20 & $-0,13$ & $-0,05$ \\
\hline F8 & 0,28 & $\underline{0,30}$ & 0,12 & $-0,15$ & $-0,07$ \\
\hline T11 & 0,00 & 0,09 & $\underline{0,71}$ & $-0,01$ & $-0,00$ \\
\hline T10 & 0,07 & 0,06 & $\underline{0,60}$ & $-0,10$ & 0,08 \\
\hline T9 & $\underline{0,32}$ & $-0,01$ & $\underline{0,49}$ & 0,08 & 0,11 \\
\hline D1 & 0,11 & $-0,08$ & $\underline{0,31}$ & $-\underline{0,31}$ & $\underline{0,40}$ \\
\hline F9 & 0,22 & 0,25 & $\underline{0,37}$ & $-0,09$ & 0,04 \\
\hline
\end{tabular}

FACTOR INTERCORRELATIONS

\begin{tabular}{lccccc}
\hline & & \multicolumn{3}{c}{$\begin{array}{c}\text { Factors } \\
\text { Openness }\end{array}$} & Agreeableness Conscientiousness Extraversion Neuroticism \\
\hline Openness & 1,00 & & & & \\
Agreeableness & 0,19 & 1,00 & & 1,00 & 1,00 \\
Conscientiousness & 0,31 & 0,10 & 1,00 & 0,26 & 1,00 \\
Extraversion & 0,36 & 0,19 & 0,40 & 0,27 & 0,26 \\
Neuroticism & 0,24 & 0,19 & & & \\
\hline
\end{tabular}

The results in Table 8 indicate that the data once more appeared to fit the specified target quite well, because loadings equal to or larger than 0,30 were obtained for 28 of the 31 expected factor loadings for four of the five factors. The four factors were Extraversion, Agreeableness, Conscientiousness and Neuroticism/Emotional Stability. Again the Conscientiousness and Extraversion dimensions were not clearly differentiated, because loadings larger than 0,30 were obtained on both dimensions for five of the subscales. The dimension Openness to Experience was not successfully rotated to the specified target, because only the Conceptual (T7) subscale was correctly targeted. Overall there were 15 loadings in the pattern matrix equal to or larger than 0,30 that were not specified.
TABLE 8

ROTATED COMPONENT MATRIX FOR THE SHL MODEL USING TARGET ROTATION

\begin{tabular}{|c|c|c|c|c|c|}
\hline $\begin{array}{l}\text { OPQ } \\
\text { scale }\end{array}$ & Openness & Agreeableness & $\begin{array}{c}\text { Factors } \\
\text { Conscientiousness }\end{array}$ & Extraversion & Neuroticism \\
\hline $\mathrm{T} 4$ & 0,29 & $\underline{0,59}$ & 0,22 & $-0,16$ & $-0,13$ \\
\hline R9 & 0,01 & $\underline{0,61}$ & 0,26 & $-0,11$ & $-0,15$ \\
\hline R5 & $\underline{0,42}$ & $\underline{0,49}$ & $-0,21$ & 0,18 & $-0,11$ \\
\hline F5 & 0,23 & 0,29 & 0,21 & $\underline{0,35}$ & $-0,22$ \\
\hline T6 & $\underline{0,33}$ & 0,28 & 0,23 & 0,10 & 0,06 \\
\hline $\mathrm{F} 4$ & $-\underline{0,56}$ & $-0,12$ & 0,26 & 0,12 & $-\underline{0,36}$ \\
\hline R7 & $-\underline{0,54}$ & 0,21 & 0,20 & 0,24 & $-\underline{0,35}$ \\
\hline $\mathrm{R} 4$ & $\underline{0,71}$ & 0,07 & $-0,14$ & 0,24 & $-0,07$ \\
\hline R1 & $\underline{0,55}$ & 0,04 & 0,23 & 0,10 & $-0,02$ \\
\hline F7 & 0,20 & 0,14 & 0,11 & 0,14 & 0,27 \\
\hline F1 & $-0,02$ & 0,07 & 0,15 & $\underline{0,74}$ & $-0,15$ \\
\hline $\mathrm{F} 2$ & $-0,21$ & 0,19 & 0,12 & $-\underline{0,74}$ & $-0,07$ \\
\hline F3 & $-0,06$ & 0,06 & $-0,08$ & $\underline{0,75}$ & 0,17 \\
\hline R6 & $\underline{0,50}$ & 0,07 & 0,06 & $\underline{0,47}$ & $-0,07$ \\
\hline T5 & $-0,18$ & $-0,03$ & $-0,15$ & $-0,29$ & 0,14 \\
\hline F10 & $\underline{0,43}$ & $-0,43$ & $\underline{0,30}$ & 0,03 & $-0,26$ \\
\hline $\mathrm{R} 8$ & $-0,16$ & $\underline{0,66}$ & 0,00 & 0,01 & $\underline{0,34}$ \\
\hline $\mathrm{R} 2$ & $\underline{0,50}$ & $-0,11$ & $\underline{0,47}$ & 0,01 & $-0,07$ \\
\hline R3 & $\underline{0,43}$ & 0,05 & $\underline{0,32}$ & 0,01 & $-0,17$ \\
\hline $\mathrm{T} 7$ & $\underline{0,32}$ & 0,05 & 0,25 & 0,02 & $\underline{0,32}$ \\
\hline $\mathrm{T} 2$ & $-0,01$ & $-0,01$ & $\underline{0,50}$ & 0,18 & $\underline{0,42}$ \\
\hline T3 & 0,14 & 0,10 & 0,04 & 0,20 & $\underline{0,43}$ \\
\hline T8 & $\underline{0,35}$ & 0,06 & $\underline{0,36}$ & 0,15 & 0,22 \\
\hline F6 & 0,17 & 0,23 & $\underline{0,31}$ & $-0,01$ & 0,22 \\
\hline $\mathrm{T} 1$ & $-0,14$ & 0,04 & $\underline{0,40}$ & $-0,09$ & $\underline{0,37}$ \\
\hline F8 & 0,16 & $-0,41$ & $\underline{0,45}$ & $-0,06$ & 0,25 \\
\hline T11 & $-0,04$ & 0,16 & $\underline{0,69}$ & $-0,01$ & $-0,20$ \\
\hline $\mathrm{T} 10$ & $-0,13$ & 0,09 & $\underline{0,67}$ & 0,08 & $-0,11$ \\
\hline T9 & 0,11 & 0,23 & $\underline{0,55}$ & 0,13 & 0,11 \\
\hline D1 & $-\underline{0,43}$ & $-0,08$ & $\underline{0,41}$ & $\underline{0,53}$ & 0,10 \\
\hline F9 & 0,10 & $-0,19$ & $\underline{0,60}$ & 0,06 & 0,07 \\
\hline
\end{tabular}

FACTOR INTERCORRELATIONS

Factors

Openness Agreeableness Conscientiousness Extraversion Neuroticism

\begin{tabular}{lccccc}
\hline Extraversion & 1,00 & & & & \\
Agreeableness & 0,18 & 1,00 & & & \\
Conscientiousness & 0,36 & 0,27 & 1,00 & & \\
Neuroticism & 0,26 & 0,23 & 0,24 & 1,00 & \\
Openness & 0,04 & 0,07 & 0,00 & 0,24 & 1,00 \\
\hline
\end{tabular}

\section{DISCUSSION}

The study was undertaken to assess whether the 31 OPQ scales could be described meaningfully in terms of a broad factor model such as the five-factor model. A well-defined six-factor model with relatively independent factors explaining 51,62\% of the variance was obtained. The measuring instruments derived from combining the OPQ subscales with high loadings on the various factors yielded psychometrically sound internal consistency reliabilities. If one considers that the OPQ subscales consist of only eight items each, the improvement in consistency of measurement when correlated subscales were combined to form six separate measuring instruments, is not surprising. The six-factor solution was chosen on the grounds of the psychological interpretability of 
its factors, in particular in relation to the Big Five model. The subscales that showed substantial loadings on the factors are presented in Table 5 with their factor loadings given in brackets. In Table 6 descriptions of the factor meanings are provided by using terminology taken directly from the respective OPQ and NEO-PI manuals. This is an attempt to show the similarity between NEO-PI-R Big Five factors and the extracted OPQ factors (Saville \& Holdsworth Ltd., 1993; Costa $\&$ McCrae, 1995).

The first factor, explaining most of the variance, was labelled as Interpersonal Relationship Harmony and is related to individuals' willingness to become involved in the feelings, problems, and welfare of others. This factor further relates to the extent of interest an individual has in the understanding of other individuals' behaviour and what motivates them to behave in a given manner. Individuals who obtained high scores on the factor are regarded as socially active persons who are sympathetic, caring and tolerant towards others and who tend to become personally involved in situations. Such individuals attempt to analyse the behaviour of others in order to understand them better. Factor 1 shows a correspondence with the empathy scale of the 16-factor model of SHL (Saville, Cramp \& Henley, 1994), but also with the sixth factor found in Chinese studies (Cheung \& Leung, 1998; Cheung, Leung, Fan, Song, Zhang \& Zhang, 1996).

The Chinese researchers (Cheung \& Leung, 1998; Cheung et al., 2001) maintained that several emic constructs from Chinese traditional culture are not found in the translated Western personality inventories that they investigated. They developed a Chinese Personality Assessment Inventory (CPAI) that included etic western personality constructs with associated facets included in the Big Five scales, but they also included emic scales that were deemed to be of specific interest to Chinese peoples (Cheung et al., 1996). In a combined factor analysis performed in a study using the CPAI and the Chinese translation of the NEO-PI, four of the Big Five factors were shared between the two personality inventories. The Openness to Experience factor was tapped by the NEO-PI only, whereas a Chinese tradition factor was defined by the CPAI scales only (Cheung \& Leung, 1998). The resemblance between the Chinese tradition factor that stresses relationship harmony and social interaction according to certain implicit rules of interpersonal relationships, and the first factor in the present study is important. It appears that the particular version of the OPQ used in the present study succeeded in measuring a combination of traits in the work context that goes beyond what the traditional Big Five inventories measure.

The representation of the various South African population groups in the sample is also important. It is often mentioned that the African characteristic of ubuntu is more typical of African than western groups. A question that arises is whether ubuntu bears a resemblance to the Chinese interpersonal relationship construct and, if it does, whether the reason why this factor emerged in the present study should be sought in the diverse nature of the sample. It is therefore uncertain whether (a) this construct emerges in non-Western cultures mainly, (b) the construct is largely omitted from Western personality inventories, or whether (c) it is included in such personality inventories, but usually not observed when the sample consists of Westerners mainly. It is suggested that future research investigate the aforementioned questions by using the latest version of the $\mathrm{OPQ}$.

The second factor was labelled Extraversion/Introversion, also referred to as Surgency (Barrick \& Mount, 1991). It deals with being forthright or spontaneous as against being reserved and restrained. More specifically, it indicates the extent to which individuals are keen to share their feelings, ideas, and viewpoints with others. A high score on this factor can be interpreted as pertaining to individuals who are sociable, jovial, vibrant and talkative. Such individuals would not hesitate to be assertive about their ideas and viewpoints. A low score implies that individuals are reserved and restrained, preferring not to share their feelings or achievements, and avoiding outbursts. This factor apparently resembles the sixth factor that Becker (1999) labelled spontaneity. This dimension clearly corresponds with scale descriptions of the Big Five factor of the NEO-PI-R (see Table 6), although the a priori predictions in Table 1 were correct for only two of the scales.

Factor 3 showed a strong correspondence to the dimension of Emotional Stability of the five-factor model (Nyfield, et al., 1995; Matthews et al., 1990) and was labelled as such. It can be interpreted as the tendency of individuals to remain calm, positive and free from anxiety, even under adverse conditions. Such persons appear socially confident and remain cheerful despite setbacks. Persons who score low on this factor get upset and worry when things are perceived to go wrong. They also cope poorly with stress and are easily hurt. Low scorers are furthermore anxious to perform well. This description of the third factor ties in neatly with the definition of Emotional Stability of the NEO-PI-R. Four subscales were correctly hypothesised to load on this factor (see Table 1).

The fourth factor consisted of scales that are associated with encouraging others to contribute to decision-making in a democratic way as against being decisive and controlling. A person who scores high on this factor prefers to listen and consult with others, managing decisions through consensus and not by means of direct instructions. A low score on this factor implies that it is not the individual's preference to consult others regarding decisions, but rather to enforce decisions. Such individuals prefer to be in control of others and will attempt to convince others of their viewpoint, often by arguing. They tend to reach conclusions hastily and hold strong opinions on issues. This factor corresponds well with the Agreeableness factor of the Big Five model and was labelled as such. It nevertheless appears to be less empathetic in nature than the corresponding NEO-PI-R factor (see Table 6 ), because the interpersonal/caring aspect measured by the OPQ was tapped already by the first factor. Four of the OPQ subscales were correctly predicted to load on Agreeableness (see Table 1). Contrary to expectation the Competitive subscale did not yield a high negative loading on this factor. In fact, its low communality value $(0,19)$ is indicative of a large proportion of specific variance that was not shared by any of the six factors.

Factor 5 is clearly one of the Big Five factors and corresponds with Openness to Experience as defined by Matthews et al. (1990) and Nyfield et al. (1995). This dimension typifies individuals who are intellectually curious. They are imaginative and conceptual thinkers who enjoy being involved with abstract, evaluative and hypothetical tasks. Individuals with high scores on this factor are creative, innovative, artistic, and culturally orientated. Four OPQ subscales were hypothesised correctly to load on this factor and the scale descriptions also correspond with the NEO-PI-R factor of Openness to Experience. The Traditional subscale that measures conventionality, did not yield a high negative loading on this factor, despite the fact that its subscale description corresponds to the description of a low score on the NEO-PI-R factor of Openness to Experience. The low communality $(0,16)$ obtained for the Traditional subscale is an indication that this scale exhibits a high degree of specific variance not shared by the Openness to Experience factor extracted here, nor any of the other five factors. A substantial proportion of measurement error due to its low alpha value may also have contributed to this finding. This subscale has been adapted for the current OPQ version and may very well load on the Openness factor in a follow-up study. 
Factor 6 affirms the Conscientiousness dimension of the fivefactor model, because the NEO-PI-R factor of Conscientiousness fits the description of the OPQ factor. Furthermore, five OPQ subscales were correctly predicted to load highly on this factor. This factor also resembles the Methodical scale of the 16-factor model proposed by SHL (Nyfield et al., 1995; Saville, Cramp \& Henley, 1994). The factor is associated with individuals' conscience, diligence and single-mindedness in completing tasks within the scheduled time limit. Individuals who have high scores on this factor are typically persons that emphasise planning, organising and the precise execution of tasks. There is a high premium on goal setting and working methodically and accurately. In contrast, low scores are associated with individuals who are not detail conscious. Such individuals are inclined to become bored with routine tasks and they are consequently not goal orientated.

The results of the present study do not correspond fully with the six-factor model proposed by Matthews et al. (1990) or the fivefactor model of Matthews and Stanton (1994). Instead, convincing support for a six-factor model that includes the wellknown Big Five factors and which is based on the work of the aforementioned researchers as well as a logical analysis of the scale contents by the authors, was obtained. To gain further insight into the applicability of the six-factor model, target rotations to partially specified targets were carried out by means of the Tarrot program (see Browne et al., 1998). The target matrices were derived from the model hypothesised in Table 1 and from a Big Five solution obtained for a British sample. The results obtained indicated that the data supported the obtained six-factor solution better than the alternative five-factor models. An interesting finding was that the South African data could not be rotated to yield the Openness to Experience dimension defined by the British sample. This result deserves further investigation, because several researchers have indicated that this dimension does not replicate well across cultures (Cheung \& Leung, 1998; Cheung et al., 2001; Heuchert et al., 2000; Triandis \& Suh, 2002).

The most notable finding of the present study was the emergence of a Relationship Harmony factor that explained the largest percentage of the variance extracted by an exploratory factor analysis. This interpersonal factor resembles the Chinese tradition factor obtained in studies performed by Cheung and Leung (1998), Cheung et al. (1996), and Cheung et al. (2001). The question arises whether a five-factor solution indeed represents the most parsimonious model to explain personality across various (non-Western) populations and contexts. The results of the present study certainly suggest that the OPQ CM 5.2 explains more variance than is contained in the Big Five model and it is done in a way that may be relevant to the diverse composition of the South African population. It is suggested that the unique circumstances of each investigation, including cultural and contextual differences between western and nonwestern samples, probably explain why the Big Five factor pattern is not found consistently.

The relatively low intercorrelations between the OPQ factors point to the independence of the obtained six factors. Personality factors that are independent of one another provide a meaningful framework for explaining personality and this was satisfactorily achieved in the present study.

Several existing personality questionnaires show substantial intercorrelations between their subscales and this is particularly the case when a large number of personality variables are assessed. If this were not true, it would not be possible, as in the present research using the $O P Q$, to reduce the number of variables to a smaller number of factors by means of factor analysis. Another example of a personality inventory that consists of several intercorrelated subscales is the Sixteen Personality Factor Questionnaire (16PF) that is used on a large scale in South Africa (Abrahams \& Mauer,
1999; Prinsloo \& Ebersöhn, 2002; Van Eeden \& Prinsloo, 1997). Substantial intercorrelations between subscales cause a large amount of redundancy in the personality profiles and they also complicate the interpretation of individual assessment results. By combining those scales that correlate highly with one another into factors, one can tap to a large extent the shared information between the subscales due to variance overlap. A smaller number of factors are also easier to interpret, but the amount of specific variance of the subscales lost by using such an approach certainly needs to be kept in mind. In an ideal situation where all the subscales load highly on their respective factors, a parsimonious model can be recommended purely on psychometric grounds. Validity data should then support the same conclusion. However, if there is much specific variance contained in the subscales, too much useful information may be lost if a parsimonious model is used. The best option to use can be determined by appropriate validity studies only.

The possible utility of narrow measurements of personality, such as the OPQ CM 5,2 scales, is not contradicted by the findings of this study. In the workplace where complex decisions regarding employees need to be made, the usefulness of a comprehensive description of personality has been indicated (Barrett et al., 1996; Cattell et al., 1992; Paunonen \& Ashton, 2001). In fact, one of the best-known Big Five instruments, the NEO-PI-R measures several facets of each of its five main factors (Costa \& McCrae, 1995). In more recent research by Ones and Viswesvaran (2001) in which they investigated the predictive validity of criterion-focused occupational personality scales (COPS), the value of narrow measurements were convincingly demonstrated. They found that, apart from Conscientiousness, COPS produced higher validities than the Big Five variables when counterproductive workplace behaviour or overall job performance was being predicted.

However, it must be realised that some narrow factors will invariably correlate highly with one another and that the internal consistency of short scales will often not be high. In contrast with several of the 31 subscales of the OPQ CM 5,2, satisfactory reliabilities were found for each of the six OPQ factors. The 31-scale structure of the OPQ CM 5,2 also yielded a certain amount of redundancy. In this study a parsimonious description of personality could be obtained by applying the broad factor model, implying that such a model underlies narrow descriptions of personality traits. The results also indicated that the use of a broad factor model could be recommended on psychometric grounds where it is deemed applicable and upon confirmation of the predictive validity of the particular model. Further research should focus on confirmation of the present findings by using the updated South African version of the OPQ (OPQ 32n).

Another aspect needs to be kept in mind when personality measurements are considered. An important use of personality tests in the workplace is for selection and placement decisions. When personality measures are included in a prediction model, multiple regression is normally used. The multicolinearity caused by narrow factors makes prediction by means of regression problematic. It is clear that a small number of broad factors stand a better chance of yielding a workable and stable prediction model that will stand the test of cross-validation.

In conclusion, the OPQ CM 5,2 appears to measure broad traits obtained in numerous other studies rather well and with satisfactory reliabilities. Similar results have been found for a British sample with the updated OPQ version, namely the OPQ $32 \mathrm{n}$, as published in the test manual (Saville \& Holdsworth, 1999). Both versions of the OPQ may therefore be used to develop formulae for predicting Big Five or Big Six dimensions. It was not the purpose of the present study to establish whether it is preferable to use narrowly defined traits 
rather than broad traits in personnel decision-making situations, because no attention was paid to the predictive validities of the constructs measured by the OPQ. It is suggested that the OPQ should be used in future research by focusing on providing further evidence for solving the bandwidth-fidelity dilemma that has been an issue for human resources practitioners for more than a decade.

\section{REFERENCES}

Abrahams, F. \& Mauer, K.F. (1999). Qualitative and statistical impacts of home language on responses to the items of the Sixteen Personality Factor Questionnaire (16PF) in South Africa. South African Journal of Psychology, 29, 76-86.

Ashton, M.C. (1998). Personality and job performance: The importance of narrow traits. Journal of Organizational Behavior, 19, 289-303.

Ashton, M.C. \& Lee, K. (2001). A theoretical basis for the major dimensions of personality. European Journal of Personality, 15 (5), 327-353.

Ashton, M.C. \& Lee, K. (2002). Six independent factors of personality variation: A response to Saucier. European Journal of Personality, 16 (1), 63-75.

Barrett, P., Kline, P., Paltiel, L. \& Eysenck, H.J. (1996). An evaluation of the psychometric properties of the Concept 5.2 Occupational Personality Questionnaire. Journal of Occupational and Organizational Psychology, 69, 1-19.

Barrick, M.R. \& Mount, M. K. (1991). The Big Five personality dimensions and job performance: A meta-analysis. Personnel Psychology, 44, 1-26.

Becker, P. (1999). Beyond the Big Five. Personality and Individual Differences, 26, 511-530.

Benet, V. \& Waller, N.G. (1995). The big seven factor model of personality description: Evidence for its cross-cultural generality in a Spanish sample. Journal of Personality and Social Psychology, 69, 701-718.

Briggs, S.R. (1989). The optimal level of measurement for personality constructs. In D.M. Buss \& N. Cantor (Eds.), Personality Psychology: Recent trends and emerging directions (pp. 1-8). New York: Springer-Verlag.

Browne, M.W. (1972a). Orthogonal rotation to a partially specified target. British Journal of Mathematical and Statistical Psychology, 25, 115-120.

Browne, M.W. (1972b). Oblique rotation to a partially specified target. British Journal of Mathematical and Statistical Psychology, 25, 207-212.

Browne, M.W., Cudeck, R., Tateneni, K. \& Mels, G. (1998). CEFA: Comprehensive Exploratory Factor Analysis. http://quantrm2.psy.ohio-state.edu/browne/

Cattell, R.B. (1947). Confirmation and clarification of primary personality factors. Psychometrika, 12, 197-220.

Cattell, R.B., Eber, W.H. \& Tatsuoka, M.M. (1992). Handbook for the $16 P F$ ( $7^{\text {th }}$ ed.) Illinois: Institute for Personality and Ability Testing.

Cheung, F.M. \& Cheung, S.F. (2003). Measuring personality and values across cultures: Imported versus indigenous measures. In W.J. Lonner, D.L. Dinnel, S.A. Hayes, \& D.N. Sattler (eds.), Online readings in psychology and culture, http://www.edu/ culture.

Cheung, F.M. \& Leung, K. (1998). Indigenous personality measures: Chinese examples. Journal of Cross-Cultural Psychology, 29 (1), 233-248.

Cheung, F.M., Leung, K., Fan,R.M., Song,W., Zhang, J-X., \& Zhang, J-P. (1996). Development of the Chinese personality assessment inventory. Journal of Cross-cultural psychology, 27 (2), 181-199.

Cheung, F.H., Leung, K., Zhang, J., Sun, H., Gan, Y., Song, W. \& $\mathrm{Xie}, \mathrm{D}$. (2001). Indigenous Chinese personality constructs: Is the five-factor model complete? Journal of Cross-Cultural Psychology, 32 (4), 407-433.
Claassen, N.C.W. (1997). Cultural differences, politics and test bias in South Africa. European Review of Applied Psychology, 47 (4), 297-307.

Costa, P.T. Jr. \& McCrae, R.R. (1992a). Four ways five factors are basic. Personality and Individual Differences, 13, 861-866.

Costa, P. T., Jr. \& McCrae, R. R. (1992b). Revised NEO Personality Inventory (NEO-PI-R) and NEO Five-Factor Inventory (NEO-FFI) professional manual. Odessa, FL: Psychological Assessment Resources.

Costa, P.T., Jr. \& McCrae, R.R. (1995). Domains and facets: Hierarchical personality assessment using the Revised NEO Personality Inventory. Journal of Personality Assessment, 64, 21-50.

Craik, K.H., Hogan, R. \& Wolfe, R.N (1993). Fifty years of personality psychology. New York: Plenum.

Cronbach, L.J. \& Gleser, G.C. (1965). Psychological tests and personnel decisions ( $2^{\text {nd }}$ ed.). Urbana,Ill: University of Illinois.

Deary, I.J. (1996). A (latent) Big Five personality model in 1915? A reanalysis of Webb's data. Journal of Personality and Social Psychology, 71, 992-1005.

De Fruyt, F. \& Furnham, A. (2000). Advances in the assessment of the five-factor model. Psychologica Belgica, 40 (2), 51-75.

Digman, J.M. (1990). Personality structure: Emergence of the five-factor model. Annual Review of Psychology, 41, 417-440.

Digman, J.M. (1997). Higher order factors of the Big Five. Journal of Personality and Social Psychology, 73, 1246-1256.

Fiske, D.W. (1971). Measuring the concepts of personality. Chicago: Aldine.

Foxcroft, C. (1997). Psychological testing in South Africa: Perspectives regarding ethical and fair practices. European Journal of Psychological Assessment, 13, 229-235.

Goldberg, L.R. (1993). The structure of phenotypic personality traits. American Psychologist, 48 (1), 26-34.

Heaven, P.C.L., Connors, J. \& Stones, C. (1994). Three or five personality dimensions? An analysis of natural language terms in two cultures. Personality and Individual Differences, 17, 181-189.

Heaven, P.C.L. \& Pretorius, A. (1998). Personality structure among black and white South Africans. Journal of Social Psychology, 138 (5), 664-667.

Heuchert, J.W.P., Parker, W.D., Stumpf, H. \& Myburgh, C.P.H. (2000). The five-factor model of personality in South African college students. American Behavioral Scientist, 44 (1), 112125.

Hogan, J. \& Hogan, R. (1989). How to measure employee reliability. Journal of Applied Psychology, 74, 273-279.

Hogan, R. \& Roberts, B.W. (1996). Issues and non-issues in the fidelity-bandwidth trade-off. Journal of Organizational Behavior, 17, 627-637.

Hough, L.M. (1992). The "Big Five" personality variablesconstruct confusion: Description versus prediction. Human Performance, 5, 139-155.

Hurtz, G.M. \& Donovan, J.J. (2000). Personality and job performance: The Big Five revisited. Journal of Applied Psychology, 85 (6), 869-879.

Jackson, D.N., Paunonen, S.V., Fraboni, M. \& Goffin, R.D. (1996). A five-factor vs. six-factor model of personality structure. Personality and Individual Differences, 20, 33-45.

John, O.P. (1990). The 'Big Five' factor taxonomy: Dimensions of personality in the natural language and in questionnaires. In L.A. Pervin (Ed.), Handbook of personality: Theory and research (pp. 66-100). New York: Guilford.

Judge, T.A., Heller, D. \& Mount, M.K. (2002). Five-factor model of personality and job satisfaction: A meta-analysis. Journal of Applied Psychology, 87 (3), 530-541.

Kanfer, R., Ackerman, P.L., Murtha, T. \& Goff, M. (1996) Personality and intelligence in industrial and organizational psychology. In: D.H. Saklofske, \& M. Zeidner, (Eds). International Handbook of Personality and Intelligence (pp. 2442) New York: Plenium. 
Laher, S. \& Leibowitz-Levy, S. (2003, September). Taking personality beyond 2000: A Millonian approach? Paper presented at the $9^{\text {th }}$ South African Psychology Congress, Johannesburg.

Matthews, G. \& Stanton, N.A. (1994). Item and scale factor analysis of the occupational personality questionnaire. Personality and Individual Differences, 6 (51), 32.

Matthews, G., Stanton, N., Graham, N.C. \& Brimelow, C. (1990). A factor analysis of the scales of the Occupational Personality Questionnaire. Personality and Individual Differences, 11, 591-596.

McAdams, D.P. (1992). The five-factor model in personality: A critical appraisal. Journal of Personality, 60, 329-361.

McCrae, R.R. (1989). Why I advocate the five factor model: Joint factor analysis of the NEO-PI with other instruments. In D.M. Buss \& N. Cantor (Eds.), Personality Psychology. Recent trends and emerging directions (pp. 80-126). New York: Springer-Verlag.

McCrae, R.R. \& Costa, Jr., P.T. (1989). Reinterpreting the MyersBriggs Type Indicator from the perspective of the five-factor model of personality. Journal of Personality, 57, 17-40.

McCrae, R.R. \& Costa, P.T., Jr. (1995). Positive and negative valence within the five-factor model. Journal of Research in Personality, 29, 443-460.

McCrae, R.R. \& Costa, P.T., Jr. (1997). Personality trait structure as a human universal. American Psychologist, 52, 509-516.

McCrae, R.R., Costa, P.T., Jr., Del Pilar, G.H., Rolland, J.P. \& Parker, W.D. (1998). Cross-cultural assessment of the fivefactor model: The Revised NEO Personality Inventory. Journal of Cross-Cultural Psychology, 29, 171-188.

McCrae, R.R. \& John, O.P (1992). An introduction to the fivefactor model and its applications. Journal of Personality, 60, 175-215.

Miller, T.R. (1991). The psychotherapeutic utility of the five factor model of personality: A clinician's experience. Journal of Personality Assessment, 57, 415-433.

Mount, M.K., Barrick, M.R. \& Stewart, G.L. (1998). Fivefactor model of personality and performance in jobs involving interpersonal interaction. Human Performance, 2, 145-165.

Murphy, K.R. (1989). Is the relationship between cognitive ability and job performance stable over time? Human Performance, 2, 183-200.

Norman, W.T. (1967). 2800 personality trait descriptors: Normative operating characteristics for a university population. Ann Arbor, University of Michigan, Department of Psychology.

Nyfield, G. (1994, April). Theory versus practice: Factor scales versus specific scales. Paper presented at the symposium, Personality and Job Performance: Big Five versus Specific traits, conducted at the meeting of the Society for Industrial and Organizational Psychology, Nashville, TN.

Nyfield, G., Gibbons, J.P., Baron, H. \& Robertson, I. (1995). The cross-cultural validity of management assessment methods. Surrey, UK: Saville \& Holdsworth.

Ones, D.S. \& Viswesvaran, C. (1996). Bandwidth-fidelity dilemma in personality measurement for selection. Journal of Organizational Behavior, 17, 609-626.

Ones, D.S. \& Viswesvaran, C. (2001). Integrity tests and other criterion-focused occupational personality scales (COPS) used in personnel selection. International Journal of Selection and Assessment, 9 (1/2), 31-39.

Ones, D.S., Viswesvaran, C. \& Schmidt, F.L. (1993). Comprehensive meta-analysis of integrity test validities: Findings and implications for personnel selection and theories of job performance (Monograph). Journal of Applied Psychology, 78, 679-703.

Paunonen, S.V. (1998). Hierarchical organization of personality and prediction of modelling. Journal of Personality and Social Psychology, 74, 538-556.

Paunonen, S.V. \& Ashton, M.C. (2001). Big Five factors and facets and the prediction of modelling. Journal of Personality and Social Psychology, 81 (3), 524-539.
Paunonen, S.V. \& Jackson, D.N. (2000). What is beyond the Big Five? Plenty! Journal of Personality, 68 (5), 821-835.

Pervin, L.A. (1994). A critical analysis of current trait theory. Psychological Inquiry, 5 (2), 103-113.

Peterson, C. (1992). Personality (2nd ed.). Orlando: Harcourt Brace - Jovanovich.

Prinsloo, C.H. \& Ebersöhn, I. (2002). Fair usage of the 16PF in personality assessment in South Africa: A response to Abrahams and Mauer with special reference to issues of research methodology. South African Journal of Psychology, $32,48-57$

Richman, W.L., Weisband, S. Kiesler, S. \& Drasgow, F. (1999). A meta-analytic study of social desirability distortion in computer administered questionnaires, traditional questionnaires, and interviews. Journal of Applied Psychology, 84 (5), 754-775.

Robertson, I.T. \& Kinder, A. (1993). Personality and job competencies: An examination of the criterionrelated validity of some personality variables. Journal of Occupational and Organizational Psychology, 66, 225-244.

Rust, J. \& Golonbok, S. (1994). Modern psychometrics. Routledge, London.

Salgado, J.F. (1997). The five factor model of personality and job performance in the European community. Journal of Applied Psychology, 82 (1), 30-43.

Salgado, J.F. (1999). Predicting job performance using personality measures based explicitly on five-factor model. Paper presented at the annual Meeting of the Society for Industrial and Organizational Psychology. Atlanta, G.A.

Saucier, G. (2002). Gone too far - or not far enough? Comments on the article by Ashton and Lee (2001). European Journal of Personality, 16 (1), 55-62.

Saville, P., Cramp, L. \& Henley, S. (1994). Occupational Personality Questionnaires manual. Esher, Surrey: Saville \& Holdsworth.

Saville, P., Holdsworth, R., Nyfield, G., Cramp, L. \& Mabey, W. (1984). Occupational Personality Questionnaires manual. Esher, Surrey: Saville \& Holdsworth.

Saville \& Holdsworth Ltd. (1993). OPQ Concept Model Manual and Users' Guide. Thames Ditton, UK: Saville \& Holdsworth.

Saville \& Holdsworth Ltd. (1999). Occupational Personality Questionnaires (OPQ 32) manual. Esher, Surrey: Saville \& Holdsworth.

Saville \& Holdsworth Ltd. (South Africa). (2003a). Study number R001. http://www.shl.co.za/asp/norms.asp?Reliability= 1 \&parentid $=85$

Saville \& Holdsworth Ltd. (South Africa). (2003b). Study number R006. http://www.shl.co.za/asp/norms.asp? Reliability $=1 \&$ parentid $=85$

Saville \& Holdsworth Ltd. (South Africa). (2003c). Study number R003. http://www.shl.co.za/asp/norms.asp?Reliability= 1 \&parentid $=85$

Saville \& Holdsworth Ltd. (South Africa). (2003d). Study number R038. http://www.shl.co.za/asp/norms.asp? Reliability $=1 \&$ parentid $=85$

Saville, P. \& Wilson, E. (1991). The reliability and validity of normative and ipsative approaches in the measurement of personality. Journal of Occupational Psychology, 64, 219- 238.

Schmidt, F. \& Hunter, J. (1992). Causal modelling of processes determining job performance. Current Directions in Psychological Science, 1, 89-92.

Schmidt, M.J. \& Ryan, A.M. (1993). The Big Five in personnel selection: Factor structure in applicant and nonapplicant populations. Journal of Applied Psychology, 78 (6), 966-974.

Schneider, R.J., Hough, L.M. \& Dunnette, M.D. (1996) Broadsided by broad traits: How to sink science in five dimensions or less. Journal of Organizational Behaviour, 17, 639-655.

Steiner, D.D. \& Gilliland, S.W. (1996). Fairness reactions to personnel selection techniques in France and the United States. Journal of Applied Psychology, 81, 134-141. 
Stewart, G.L. (1999). Trait bandwidth and stages of job performance: Assessing differential effects for conscientiousness and its subtraits. Journal of Applied Psychology, 84 (6), 959-968.

Triandis, H.C. \& Suh, E.M. (2002). Cultural influences on personality. Annual Review of Psychology, 53 (1), 133-160.

Van der Walt, H.S., Meiring, D., Rothmann, S. \& Barrick, M.R. (2002). Meta-analysis of the relationship between personality measurements and job performance in South Africa. Paper presented at the $5^{\text {th }}$ Annual Industrial Psychology Conference, June, Pretoria.

Van de Vijver, F. (2002). Current trends in cross-cultural research. Paper presented at the Rand Afrikaans University, Johannesburg.

Van Eeden, R. \& Prinsloo, C.H. (1997). Using the South African version of the $16 \mathrm{PF}$ personality questionnaire in a multicultural context. South African Journal of Psychology, 27, 151-159.

Visser, D. \& De Jong, A. (2001). Comparing fairness perceptions of personnel selection techniques of American, French, and South African job applicants. Journal of Industrial Psychology, 27 (2), 62-68.

Viswesvaran, C. \& Ones, D.S. (2000). Measurement error in 'Big Five factors' personality assessment: Reliability generalization across studies and measures. Educational and Psychological Measurement, 60 (2),

Widiger, T.A. \& Trull, T.J. (1997). Assessment of the five-factor model of personality. Journal of Personality Measurement, 68 (2), 228-250. 